\title{
Clinical and sociodemographic correlates of preterm deliveries in two tertiary hospitals in southern Nigeria
}

\author{
${ }^{1}$ Mudiaga E. Zini and ${ }^{2}$ Lawrence O. Omo-Aghoja
}

Ghana Med J 2019; 53(1): 20-28 http://dx.doi.org/10.4314/gmj.v53i1.4

\author{
${ }^{1}$ Department of Obstetrics and Gynaecology, Epsom General Hospital, Epsom, Surrey, United Kingdom; \\ ${ }^{2}$ Department of Obstetrics and Gynecology, Faculty of Clinical Medicine, College of Health Sciences, Delta \\ State University, Abraka, Nigeria
}

Corresponding author: Lawrence Omo-Aghoja

E-mail: Eguono_2000@yahoo.com

Conflict of interest: None declared

\section{SUMMARY}

Background: To determine the prevalence of preterm delivery and identify the associated risk factors.

Design: This was a five - month prospective case control study of two cohorts of women who had preterm and term deliveries.

Setting: Central Hospital (CH), Warri, and Delta State University Teaching Hospital (DELSUTH), Oghara, respectively in southern Nigeria.

Participants: 522 women which consisted of 174 who presented in preterm labour or with preterm prelabour rupture of membranes as cases and 348 parturient with term deliveries served as controls.

Interventions: The study was conducted from May $1^{\text {st }} 2015$ to September $30^{\text {th }} 2015$. Socio - demographic characteristics, past gynaecological/obstetric factors, maternal/obstetric factors, and fetal outcomes were compared, and associations between these variables and gestational age at delivery were determined.

Main outcome measures: Prevalence of preterm delivery associated clinical and socio-demographic correlates and the fetal salvage rates.

Results: The incidence of preterm birth was $16 \%$. Maternal age $(p<0.002)$, parity $(p<0.000)$, booking status $(p<$ $0.000)$, and socio - economic class $(p<0.000)$ were significantly associated with preterm births. Others were multiple pregnancy $(p<0.000)$, pre - eclampsia/eclampsia $(p<0.000)$, anaemia $(p<0.000)$, malaria $(p<0.000)$, UTI $(p$ $<0.012)$, premature rupture of membrane $(p<0.000)$ and antepartum haemorrhage $(p<0.000)$. Fetal salvage rate was zero for extreme preterm neonates and $100 \%$ at late preterm.

Conclusion: Preterm birth was common, with well-defined correlates and predictors. The fetal salvage rates were significantly different across the categories of preterm neonates.

Funding: The study was self-funded by the authors

Keywords: preterm, gestational age, parity, Nigeria, risk factors, pregnancy, prevalence

\section{INTRODUCTION}

Globally, about thirteen million preterm babies are born each year. ${ }^{1-6}$ Preterm birth, defined as birth before 37 completed weeks of gestation, is a major clinical problem associated with perinatal mortality, severe neonatal morbidity and moderate to severe childhood disability. ${ }^{1,7-11}$ The percentage of preterm deliveries has risen steadily over the last two decades. Most of this increase has been among children born at 32 to 36 weeks gestation. ${ }^{12,13}$ Although only $5-11 \%$ of births occur preterm, they account for about $85 \%$ of early neonatal deaths in normally formed babies and up to $75 \%$ of perinatal mortality in some series. $3,7,9-11$
While only $0.87 \%$ of all live births occur at a gestational age less than 31 weeks, births below this gestational age are responsible for $84 \%$ of the neonatal mortalities among infants of all gestational ages. ${ }^{10}$ Compared with infants born at term, preterm infants have a much greater risk of death and disability. ${ }^{12}$ In Nigeria, preterm babies account for $40-60 \%$ of all perinatal deaths. ${ }^{11}$ By gestational age, $5.2 \%$ of preterm births occur at less than 28 weeks gestation (extremely preterm), $10.4 \%$ at $28-$ $<32$ weeks (very preterm), and $85.3 \%$ at $32-36$ weeks (Moderate - late preterm)., ${ }^{4,6,14-16}$ 
Preterm delivery could be spontaneous or induced. ${ }^{12,16-18}$ Clinical and socio-demographics variables which are usually not apparent have been associated with spontaneous preterm delivery.,9-1116,18-20 Preterm neonates are more likely to have difficulty with feeding, blood glucose control, jaundice, temperature instability, apnoea, respiratory distress, sepsis, wide spectrum of neuro-developmental disabilities, as well as growth and health problems either singly or in combination compared to neonates delivered at term. ${ }^{12,13,18}$ Consequent upon these complications, the birth of a preterm neonate can bring with it considerable emotional and economic costs to families with its attendant implications for public-sector services. ${ }^{12,16,17}$ The United States in 2005, estimated the annual societal economic burden associated with preterm birth at $\$ 26.2$ billion minimum. $^{12}$

The survival of preterm infants is a function of both their biological maturity and technological advancement of any given setting. While technological advancement has continued to show marked improvement in developed countries with increasing survival of extremely preterm babies $^{11,17}$, the same cannot be said of the developing countries. especially in Africa where there is poor health infrastructure, poverty, mass illiteracy, gross gender inequality and numerous conflicts, and lack of equipment, manpower, and support services necessary to float a functioning neonatal intensive care service. ${ }^{11,17}$ In the light of this, the plausible way of reducing the burden of preterm birth on our health sector is by reducing its incidence, starting with a proper understanding of the factors associated with these births. ${ }^{17,18}$

It is against this backdrop that this study was conceptualized with the overall aim of determining the prevalence of preterm delivery in Delta State University Teaching Hospital and Central Hospital Warri, in Delta State, identify the associated clinical and sociodemographic correlates and compute the fetal salvage rates for the different categories of preterm births. This will certainly add to the existing data on preterm delivery both at the local, regional and national level as well as facilitate the formulation of appropriate interventions that will help reduce the burden of preterm births and optimize perinatal outcomes.

\section{METHODS}

The study was conducted over a 5-month period, May $1^{\text {st }}$ 2015 to September 30 2015 at the Central Hospital (CH), Warri, Delta State and Delta State University Teaching Hospital (DELSUTH), Oghara, Delta State respectively in southern Nigeria.
The combined average monthly delivery rate is 400 and a combined average annual delivery rate of 4000; of these, about 25\% (100) are preterm deliveries. Both hospitals are equipped with neonatal intensive care unit run by Neonatologists, resident Doctors, and neonatal care nurses. It was a prospective case - control study. The cases were women who presented in preterm labour or with preterm prelabour rupture of membranes at the gestation ages of 24 weeks completed to 36 weeks plus 6 days, and subsequently progressed to have preterm delivery. For each case of preterm delivery, the next two consecutive parturients with term deliveries served as controls. The term deliveries were between 37 weeks completed and 41 weeks plus 6 days. The limit of viability for this study was 24 weeks and preterm births were sub - classified into extremely preterm ( <28 weeks), very preterm ( $28-31$ weeks), moderate preterm $\left(32-33\right.$ weeks) and late preterm $(34-36 \text { weeks })^{14}$. Stillbirths for the purpose of this study were babies born without signs of life at $\geq 24$ weeks gestational age.

In both cases and controls, only parturients who were sure of their last normal menstrual period or had an early obstetric ultrasound scan, had regular menstrual cycles prior to pregnancy and had not used hormonal contraception in the preceding three months prior to pregnancy were recruited. Women who delivered post term ( $\geq 42$ weeks), and those whose babies had gross congenital malformations were excluded from the study.

Participants were counselled about the study following which informed consent was obtained. Upon recruitment, data sheet designed for the purpose was used to extract sociodemographic and clinical information through oral interview and complete physical examination of the participants. The results of investigations conducted were also recorded. After delivery, information on the type of delivery as well as mode of delivery were documented. Fetal outcome with regard to stillbirths, early neonatal deaths, defined as deaths within the first 7 days after birth, and admission into the neonatal intensive care unit was also documented.

Parturients discharged within the first week post-delivery were followed up via daily telephone calls as adverse neonatal events might have occurred post discharge. This was used in estimating the fetal salvage rate which was calculated using the formula below:

Fetal Salvage Rate $(\%)$ FSR $=\frac{F(\text { alive }) \times 100}{F \text { (total) }}$ Where FSR

$=$ Fetal salvage rate, $\mathrm{F}$ (alive): number of neonates alive after 7days in preterm category; and F (total): number of live births in preterm category. 
The socio - economic status of parturients was determined using the educational and occupational status of the parturients and their spouses/consorts according to Oyedeji's model where parturients were grouped into class I, II, III, IV and V. Classes I - III corresponded to upper class while IV and V corresponded to the lower class. ${ }^{19}$ The total number of deliveries during the study period was obtained and used in calculating the prevalence of preterm delivery. The study was approved by the Health Research and Ethics Committee of both study centres (DELSUTH/HREC/2014/025 and CHW/ECC/VOL 1/47).

The minimum sample size calculated using OpenEpi ${ }^{20}$ was 522. This consisted of 174 cases and 348 controls in a ratio of 1:2. The recorded data was coded and fed into the computer using the Statistical Package for Social Sciences (SPSS Inc., Chicago Il., USA) software version 20 and this was also used for the analysis of the data which consisted of univariate and bivariate analysis, and comparison of identified relationships. Test of statistical significance were based on $95 \%$ confidence interval $(\mathrm{p}<0.05)$ using the $\mathrm{X}^{2}$ test with Yates or Fischer exact correction where applicable. Logistic regression analysis was conducted to evaluate the strength of associations between multiple independent variables and pre-term delivery with a view to eliminate effects of potential confounding variables.

\section{RESULTS}

This was a case control study involving 174 women who delivered preterm and 348 women who delivered at term. There was a total of 2,200 deliveries during the study period. Of these there were 1,850 term and 350 preterm deliveries. This gave a preterm delivery incidence rate of $16 \%$. The data obtained following analysis are presented in Tables 1-6.

Table 1 shows the socio-demographic characteristics, past obstetric and gynaecological history of parturients. The mean age for the cases was $29.9 \pm 5.7$ years and the mean age of the controls was $30.4 \pm 5.1$ years. Statistically significant higher proportions of 15-19, 25-29 and >40 year olds were in the preterm category $(\mathrm{p}<0.0002)$. The parturients with preterm births had statistically significant higher proportions of primigravidae and grand multiparous women ( $p<0.001)$. Furthermore, $20.7 \%$ of parturients with preterm births were unbooked, compared with parturients who had term delivery in which only $5.2 \%$ were un-booked. Similarly, parturients with preterm delivery were predominantly of low socioeconomic status compared to parturients with term delivery, with the difference being statistically significant ( $\mathrm{p}$-value $<0.001)$.
Table 2 shows the Past obstetric and gynaecologic history of the participants. The history of previous preterm birth, frequency of preterm births, previous termination of pregnancy and frequency of termination of pregnancy were similar in both cases and control and did not show any significant association with preterm births.

Table 3 shows the Medical and Obstetric conditions in index pregnancy of parturients. Thirty-three (19\%) parturients with preterm births and 7 (2.0\%) parturients with term births had multiple pregnancies respectively. This difference was statistically significant ( $\mathrm{p}$-value < 0.001). Similarly, parturients with preterm births predominantly suffered pre-eclampsia and eclampsia compared with parturients who had term delivery ( $\mathrm{p}$ value $<0.001)$.

Table 1 Socio - demographic variables of parturients at term and preterm

\begin{tabular}{|c|c|c|c|}
\hline \multirow{3}{*}{\multicolumn{2}{|c|}{ Variables }} & \multicolumn{2}{|c|}{ Gestational age category } \\
\hline & & \multirow{2}{*}{$\begin{array}{c}\text { Preterm } \\
\mathrm{N}(\%) \\
\end{array}$} & \multirow{2}{*}{$\begin{array}{l}\text { Term } \\
\mathrm{N}(\%) \\
\end{array}$} \\
\hline & & & \\
\hline \multirow[t]{7}{*}{\begin{tabular}{|l|} 
Age Group \\
\end{tabular}} & $15-19$ & $10(5.7)$ & $3(0.9)$ \\
\hline & $20-24$ & $13(7.5)$ & $45(12.9)$ \\
\hline & $25-29$ & $49(28.2)$ & $78(22.4)$ \\
\hline & $30-34$ & $64(36.8)$ & $153(44.0)$ \\
\hline & $35-39$ & $30(17.2)$ & $60(17.2)$ \\
\hline & $>40$ & $8(4.6)$ & $9(2.6)$ \\
\hline & Total & $174(100.0)$ & $348(100.0)$ \\
\hline \multirow[t]{4}{*}{ Parity Group } & & $67(385)$ & $84(24.1)$ \\
\hline & \begin{tabular}{|l|}
$1-4$ \\
\end{tabular} & $89(51.1)$ & $249(71.6)$ \\
\hline & $>5$ & $18(10.3)$ & $15(4.3)$ \\
\hline & Total & $174(100.0)$ & $348(100.0)$ \\
\hline \multirow[t]{3}{*}{ Booking Status } & Booked & $138(79.3)$ & $330(94.8)$ \\
\hline & Unbooked & $36(20.7)$ & $18(5.2)$ \\
\hline & Total & $174(100.0)$ & $348(100.0)$ \\
\hline \multirow[t]{5}{*}{ Marital Status } & & & \\
\hline & \begin{tabular}{|l} 
Married \\
Single
\end{tabular} & $159(91.4)$ & $\begin{array}{l}318(91.4) \\
15(4.3)\end{array}$ \\
\hline & Cohabitin & $3(1.7)$ & $15(4.3)$ \\
\hline & & & \\
\hline & Total & $174(100.0)$ & $348(100.0)$ \\
\hline \multirow[t]{5}{*}{ Socio-Economic Class } & 1.00 & $22(12.6)$ & $69(19.8)$ \\
\hline & 2.00 & $36(20.7)$ & $123(35.3)$ \\
\hline & 3.00 & $76(43.7)$ & $124(35.6)$ \\
\hline & 4.00 & $40(23.0)$ & $32(9.2)$ \\
\hline & Total & $174(100.0)$ & $348(100.0)$ \\
\hline
\end{tabular}

They were also more likely to be anaemic (27\% versus $5.2 \%$ respectively), have suffered malaria (12.6\% versus $3.4 \%)$, had urinary tract infection $(5.7 \%$ versus $1.7 \%$ ), suffered PROM (32.8\% versus $1.7 \%$ ), and had APH $(6.9 \%$ versus $3.7 \%)$. These differences were statistically significant ( $\mathrm{p}$-values $<0.001)$. Though the proportion of those who had abdominal massage was higher in parturients with preterm births compared to those with 
term births, the differences were not statistically significant ( $\mathrm{p}$-value $<0.111)$.

Table 2 Past obstetric and gynaecologic history of the parturients

\begin{tabular}{|c|c|c|c|}
\hline \multirow[t]{3}{*}{ Variables } & & \multicolumn{2}{|c|}{ Gestational age category } \\
\hline & & Preterm & Term \\
\hline & & $\mathrm{N}(\%)$ & $\mathrm{N}(\%)$ \\
\hline \multirow{3}{*}{$\begin{array}{l}\text { Previous } \\
\text { Birth }\end{array}$} & n YES & $12(6.9)$ & $12(3.4)$ \\
\hline & NO & 162(93.1) & $336(96.6)$ \\
\hline & Total & $174(100.0)$ & $348(100.0)$ \\
\hline \multirow{5}{*}{$\begin{array}{l}\text { Frequency } \\
\text { Preterm Births }\end{array}$} & $\mathrm{f} .00$ & $162(93.1)$ & $336(96.6)$ \\
\hline & 1.00 & $12(6.9)$ & $12(3.4)$ \\
\hline & 2.00 & $0(0.0)$ & $0(0.0)$ \\
\hline & 3.00 & $0(0.0)$ & $0(0.0)$ \\
\hline & Total & $174(100.0)$ & $348(100.0)$ \\
\hline \multirow{3}{*}{$\begin{array}{l}\text { Previous Terminatior } \\
\text { Of Pregnancy }\end{array}$} & nYES & $90(51.7)$ & $174(50.0)$ \\
\hline & NO & $84(48.3)$ & $174(50.0)$ \\
\hline & Total & $174(100.0)$ & $348(100.0)$ \\
\hline \multirow{5}{*}{$\begin{array}{l}\text { Frequency } \\
\text { termination } \\
\text { Pregnancy }\end{array}$} & $f \mid .00$ & $84(48.3)$ & $174(50.0)$ \\
\hline & 1.00 & $23(13.2)$ & $63(18.1)$ \\
\hline & 2.00 & $36(20.7)$ & $57(16.4)$ \\
\hline & 3.00 & $31(17.8)$ & $54(15.5)$ \\
\hline & Total & $174(100.0)$ & $348(100.0)$ \\
\hline
\end{tabular}

Table 3 Medical/Obstetric conditions in index pregnancy of the parturients

\begin{tabular}{|c|c|c|c|}
\hline \multirow[t]{3}{*}{ Variables } & & \multicolumn{2}{|c|}{ Gestational age category } \\
\hline & & \multirow{2}{*}{\begin{tabular}{|l|} 
Preterm \\
$\mathrm{N}(\%)$ \\
\end{tabular}} & \multirow{2}{*}{$\begin{array}{l}\text { Term } \\
\mathrm{N}(\%) \\
\end{array}$} \\
\hline & & & \\
\hline \multirow[t]{3}{*}{ Multiple Pregnancy } & YES & \begin{tabular}{|l}
$33(19.0)$ \\
\end{tabular} & $7(2.0)$ \\
\hline & NO & $141(81.0)$ & $341(98.0)$ \\
\hline & Total & 174(100.0) & $348(100.0)$ \\
\hline \multirow{3}{*}{$\begin{array}{l}\text { Preeclampsia/Eclam } \\
\text { psia }\end{array}$} & YES & $86(49.4)$ & $51(14.7)$ \\
\hline & $\mathrm{NO}$ & $88(50.6)$ & $297(85.3)$ \\
\hline & Total & $174(100.0)$ & $348(100.0)$ \\
\hline \multirow{3}{*}{ Haematocrit } & $<30 \%$ & $48(27.6)$ & $18(5.2)$ \\
\hline & $>30 \%$ & $126(72.4)$ & $330(94.8)$ \\
\hline & Total & $174(100.0)$ & $348(100.0)$ \\
\hline \multirow[t]{3}{*}{ Malaria } & YES & $22(12.6)$ & $12(3.4)$ \\
\hline & NO & $152(87.4)$ & $336(96.6)$ \\
\hline & Total & $174(100.0)$ & $348(100.0)$ \\
\hline \multirow[t]{3}{*}{ UTI } & YES & $10(5.7)$ & $6(1.7)$ \\
\hline & NO & $164(94.3)$ & $342(98.3)$ \\
\hline & Total & $174(100.0)$ & $348(100.0)$ \\
\hline \multirow[t]{3}{*}{ PROM } & YES & $57(32.8)$ & $6(1.7)$ \\
\hline & NO & $117(67.2)$ & $342(98.3)$ \\
\hline & Total & $174(100.0)$ & $348(100.0)$ \\
\hline \multirow[t]{3}{*}{ APH } & YES & $18(10.3)$ & $6(1.7)$ \\
\hline & NO & $156(89.7)$ & $342(98.3)$ \\
\hline & Total & 174(100.0) & $348(100.0)$ \\
\hline \multirow[t]{3}{*}{ Abdominal Massage } & YES & $12(6.9)$ & $13(3.7)$ \\
\hline & NO & $162(93.1)$ & $335(96.3)$ \\
\hline & Total & $174(100.0)$ & $348(100.0)$ \\
\hline
\end{tabular}

Table 4 shows the multiple logistic regression of risk factors for preterm delivery. Two variables, frequency of preterm birth and $\geq 3$ previous TOP were excluded from the analysis due to high collinearity.
Table 4 Multiple Logistic Regression of risk factors for preterm delivery

\begin{tabular}{|l|l|l|l|}
\hline & \multirow{2}{*}{$\begin{array}{c}|c| \\
\text { Odds } \\
\text { Ratio }\end{array}$} & \multicolumn{2}{|c|}{$\begin{array}{l}\text { Confidence Interval } \\
\text { Upper }\end{array}$} \\
\cline { 1 - 1 } Lower
\end{tabular}

Multiple logistic regression analysis was performed using gestational age as the independent variable and the listed variables as dependent co-variate. 
The identified predictors of preterm delivery were parity, previous preterm birth, multiple pregnancies, preeclampsia, anaemia, malaria, urinary tract infection (UTI), PROM, antepartum haemorrhage (APH) and abdominal massage.

PROM remained the single most important predictor with the highest odds for preterm delivery $(\mathrm{OR}=59.93$, 95\% CI, 21.307-168.566). Similarly, parturients who suffered pre-eclampsia/eclampsia syndrome, APH, and multiple pregnancies respectively had about 17,14 , and 8 folds odds of having a preterm delivery $(\mathrm{OR}=17.277$, $95 \% \mathrm{CI}, 9.177-32.528),(\mathrm{OR}=14.840,95 \% \mathrm{CI}, 4.360-$ 50.510) and $(\mathrm{OR}=8.521,95 \% \mathrm{CI}, 2.546-28.518)$. Additionally, women with malaria $(\mathrm{OR}=3.690,95 \% \mathrm{CI}$, $1.272-10.706)$, grand multiparity $(\mathrm{OR}=3.563,95 \% \mathrm{CI}$, 1.092-11.628), and previous preterm delivery (OR = 3.100, 95\% CI, 1.077-8.926) had about 3-fold probability of having preterm births. Anaemic women also had about 3 -fold chance of preterm delivery $(\mathrm{OR}=2.728,95 \% \mathrm{CI}$, 1.166-6.384). Abdominal massage had over 2-fold odds of having preterm birth though this did not show statistical significance.
Table 5 shows the Pattern of foetal outcome among parturients who delivered preterm. There was statistically significant differences in the pattern of foetal outcome [stillbirth and NICU admission rates in particular] ( $p<$ $0.000)$, neonatal weight $(p<0.000)$, and fifth minute Apgar score $(p<0.022)$. The probability of having a stillbirth was significantly higher in parturients who delivered at a gestational age of 24-27 weeks and least in those of gestational age of 34-36 weeks. The majority of early and moderately preterm neonates were admitted in the NICU. The main indication for admission was prematurity. Majority of the neonates in the late term group had normal Apgar scores compared to the early and moderate preterms, where mild birth asphyxia predominated.

Table 6 displays the Foetal salvage rates. The foetal salvage rate was $100 \%$ at $32-33$ weeks gestation but was $0 \%$ at 24-27 weeks in both study centres.

Table 5: Pattern of foetal outcome among parturients who delivered preterm

\begin{tabular}{|c|c|c|c|c|c|}
\hline \multirow{3}{*}{\multicolumn{2}{|c|}{ Variables }} & \multicolumn{4}{|c|}{ GESTATIONAL AGE GROUPS } \\
\hline & & \multicolumn{4}{|c|}{ 24-27WKS 28-31WKS 32-33WKS 34-36WKS } \\
\hline & & \multirow{2}{*}{$\begin{array}{l}\mathrm{N}(\%) \\
7(70.0) \\
\end{array}$} & \multirow{2}{*}{$\begin{array}{l}\mathrm{N}(\%) \\
8(22.9)\end{array}$} & \multirow{2}{*}{$\begin{array}{l}\mathrm{N}(\%) \\
6(23.1) \\
\end{array}$} & \multirow{2}{*}{$\begin{array}{c}\mathrm{N}(\%) \\
12(11.7) \\
\end{array}$} \\
\hline \multirow[t]{5}{*}{ Fetal Outcome } & STILLBIRTH & & & & \\
\hline & ENND & $0(0.0)$ & $1(2.9)$ & $0(0.0)$ & $3(2.9)$ \\
\hline & NICU & $3(30.0)$ & $26(74.3)$ & $16(61.5)$ & $33(32.0)$ \\
\hline & WITH MOTHER & $0(0.0)$ & $0(0.0)$ & $4(15.4)$ & $55(53.4)$ \\
\hline & Total & $10(100.0)$ & $35(100.0)$ & $26(100.0)$ & $103(100.0)$ \\
\hline \multirow{6}{*}{$\begin{array}{l}\text { Neonatal } \\
\text { Group }\end{array}$} & $\mathrm{t}<1.0 \mathrm{~kg}$ & $8(80.0)$ & $3(8.6)$ & $0(0.0)$ & $0(0.0)$ \\
\hline & $1.0-1.49 \mathrm{~kg}$ & $2(20.0)$ & $20(57.1)$ & $3(11.5)$ & $3(2.9)$ \\
\hline & $1.5-2.49 \mathrm{~kg}$ & $0(0.0)$ & $11(31.4)$ & $17(65.4)$ & $41(39.8)$ \\
\hline & $2.5-3.99 \mathrm{~kg}$ & $0(0.0)$ & $1(2.9)$ & $6(23.1)$ & $59(57.3)$ \\
\hline & $\geq 4.0 \mathrm{~kg}$ & $0(0.0)$ & $0(0.0)$ & $0(0.0)$ & $0(0.0)$ \\
\hline & Total & $10(100.0)$ & $35(100.0)$ & $26(100.0)$ & $103(100.0)$ \\
\hline \multirow{5}{*}{$\begin{array}{l}\text { 5th Minute Apgar } \\
\text { Score }\end{array}$} & r AS $<4$ & $0(0.0)$ & $0(0.0)$ & $0(0.0)$ & $0(0.0)$ \\
\hline & AS $4 \& 5$ & $2(66.7)$ & $5(18.5)$ & $0(0.0)$ & $5(5.5)$ \\
\hline & AS 6 & $1(33.3)$ & $13(48.1)$ & $12(60.0)$ & $33(36.3)$ \\
\hline & AS > 6 & $0(0.0)$ & $9(33.3)$ & $8(40.0)$ & $53(58.2)$ \\
\hline & Total & $3(100.0)$ & $27(100.0)$ & $20(100.0)$ & $91(100.0)$ \\
\hline \multirow{4}{*}{\begin{tabular}{|l} 
Indication For \\
NICU Admission \\
\end{tabular}} & Prematurity & $2(66.7)$ & $21(80.8)$ & $8(50.0)$ & $14(42.4)$ \\
\hline & Severe Birth Asphyxia & $0(0.0)$ & $3(11.5)$ & $3(18.8)$ & $8(24.2)$ \\
\hline & \begin{tabular}{|ll}
$\begin{array}{l}\text { Presumed } \\
\text { Sepsis }\end{array}$ & Neonatal \\
\end{tabular} & $1(33.3)$ & $2(7.7)$ & $5(31.2)$ & 11(33.3) \\
\hline & Total & $3(100.0)$ & $26(100.0)$ & $16(100.0)$ & $33(100.0)$ \\
\hline
\end{tabular}

Yates's corrected Chi square:

Fetal outcome: : $x^{2}=51.874, p$-value $=0.000$

Neonatal weight group: : $x^{2}=156.841, p$-value $=0.000$

$5^{\text {th }}$ minute APGAR Score: : $x^{2}=14.762, p$-value $=0.022$

NICU: : $x^{2}=7.19$, p-value 0.304 
Table 6 Foetal salvage rates for parturients in DELSUTH/Central Hospital Warri

\begin{tabular}{|c|c|c|c|c|c|c|c|}
\hline \multirow[t]{3}{*}{ Variables } & & & & \multirow{2}{*}{\multicolumn{4}{|c|}{\begin{tabular}{|l|} 
GESTATIONAL AGE GROUPS \\
\end{tabular}}} \\
\hline & & & & & & & \\
\hline & & & & \multirow{2}{*}{\begin{tabular}{|c|} 
24-27WKS \\
$\mathrm{N}(\%)$ \\
$0(0.0)$ \\
\end{tabular}} & \multirow{2}{*}{$\begin{array}{c}\text { 28-31WKS } \\
\mathrm{N}(\%) \\
12(54.5) \\
\end{array}$} & \multirow{2}{*}{$\begin{array}{l}\text { 32-33WKS } \\
\mathrm{N}(\%) \\
9(100.0)\end{array}$} & \multirow{2}{*}{$\begin{array}{l}\text { 34-36WKS } \\
\mathrm{N}(\%) \\
18(100.0)\end{array}$} \\
\hline \multirow{9}{*}{ Place of Delivery } & \multirow{3}{*}{ DELSUTH } & \multirow{3}{*}{ Foetal Status 8th Day } & ALIVE & & & & \\
\hline & & & DEAD & $1(100.0)$ & $10(45.5)$ & $0(0.0)$ & $0(0.0)$ \\
\hline & & & Total & $1(100.0)$ & $22(100.0)$ & $9(100.0)$ & $18(100.0)$ \\
\hline & \multirow{3}{*}{ CHW } & \multirow{3}{*}{ Foetal Status 8th Day } & ALIVE & $0(0.0)$ & $3(60.0)$ & $11(100.0)$ & $70(95.9)$ \\
\hline & & & DEAD & $2(100.0)$ & $2(40.0)$ & $0(0.0)$ & $3(4.2)$ \\
\hline & & & Total & $2(100.0)$ & $5(100.0)$ & $11(100.0)$ & $73(100.0)$ \\
\hline & \multirow{3}{*}{ Total } & \multirow{3}{*}{ Foetal Status 8th Day } & ALIVE & $0(0.0)$ & $15(55.6)$ & $20(100.0)$ & $88(96.7)$ \\
\hline & & & DEAD & $3(100.0)$ & $12(44.4)$ & $0(0.0)$ & $3(3.3)$ \\
\hline & & & Total & $3(100.0)$ & $27(100.0)$ & $20(100.0)$ & $91(100.0)$ \\
\hline
\end{tabular}

Yates's corrected Chi square:

DELSUTH: $x^{2}=11.503, p<0.009$

CHW: $\quad x^{2}=17.281, p<0.001$

\section{DISCUSSION}

The results demonstrated that preterm birth was common in the study centres, with well-defined correlates and predictors. The fetal salvage rates were also significantly different across the categories of preterm neonates. The incidence of preterm delivery in this study of $16 \%$ is at variance with reports of previous studies from different regions of Nigeria, West African and European Nations. It was higher than previously reported in some instances ${ }^{9,11,16,27,30}$ and lower in other instances. ${ }^{17}$

Differences in methodology of the respective studies is thought to have partly accounted for this, considering the fact that therapeutic/medically indicated preterm deliveries were excluded from the findings of Ezechi et al, and Mukuolu excluded multiple gestation. It was not apparent why a high incidence was found in Kunle Olowu's study, however it is possible that the HIV positive status of the women in the study population was a contributory factor.

The results indicated that premature rupture of membrane was the strongest predictor of preterm birth as pregnancies which were complicated by preterm rupture of membrane in this study were almost sixty times more likely to end in preterm delivery when compared to those without PROM. The risks of preterm births were also significantly elevated in women with pre-eclampsia and eclampsia, antepartum haemorrhage and multiple pregnancy.

These findings compare favourably with reports of previous studies. $3,5,11,26-29,30,33,42$ Majority of women who presented with preeclampsia/eclampsia were preterm and their deliveries were indicated to halt the progression of the disease process and its consequences. Again multiple pregnancy is associated with a variety of complications usually necessitating early delivery and these includes preterm prelabour rupture of membranes, preterm labour and increased intervention from medical and obstetric complications. $^{7,21,22}$

Socio - demographic factors also showed some association with preterm births in this study. Extremes of reproductive age group, primigravidity and grandmultiparity, being unbooked, and low socioeconomic status were shown on bivariate analysis to be statistically significantly associated with preterm births, however on multivariate logistic regression model these association were attenuated except for parity that showed consistent association with the risk of preterm births with almost a 4-fold risk.

Our findings from the multivariate logistic regression analysis in which there was attenuation of the strength of socio-demographic variables being strong predictors of preterm birth is consistent with reports of earlier works. ${ }^{3,10,11,27-30,33,41}$ Similarly, earlier reports are in agreement with the finding of this study that only parity remained consistently a significant risk factor for preterm births. ${ }^{7,10,11,29}$ The implication of this is that the present study failed to show a strong independent association of sociodemographic variables except for parity with the risk of preterm birth. The potential effects of sociodemographic characteristics is therefore modulated by other intermediating factors (medical and obstetric parameters) that triangulate with them to bring about preterm births. This study further underscores the fact that health seeking behaviour in our setting is not totally a function of being booked or the patient's socioeconomic status.

This study unlike previous reports ${ }^{7,26-28,34,35}$ did not associate marital status with the risk of preterm delivery. However, Umeora et al and Mokuolu et al ${ }^{11,30}$ reported similar finding as noted in this study in their respective works. We hypothesize that this finding is predicated on the homogeneity of the marital status of the cases and controls in this study. 
Interestingly this study found on bivariate analysis that previous preterm birth was not a significant predictor of preterm delivery, and this seem to be contrary to findings of several other local and international studies. ${ }^{3,7,10,11,18,21,23-26}$

A few other studies had also found similarly that there was no association between previous preterm birth and the risk for preterm delivery. ${ }^{27,33}$ However on multivariate logistic regression analysis, previous preterm delivery was shown to increase the risk for preterm birth by over 3 -fold chance (Odds ratio $=3.100$, $95 \% \mathrm{CI}=1.077-8.926)$. This certainly gives credence to its importance as a predictor of preterm birth. Previous termination of pregnancy was not significantly associated with preterm delivery in this study, as also shown by a few previous Nigerian studies, ${ }^{10,27,29}$ but contrast with the findings of several other studies where previous termination of pregnancy was associated with preterm delivery. ${ }^{10,21,23,26,27}$ The exact reason for this we are unable to explain, and we suggest further research in this regard.

The practice of 'rubbing', otherwise referred to in this study as 'abdominal massage' is one peculiar to the Niger - Delta region of Nigeria. It involves repeated massage of the abdomen of pregnant women by traditional birth attendants including the external manipulation of the fetus akin to external cephalic version.

This is usually vigorous and cuts across booked and unbooked parturients. It is thought to improve the wellbeing of the foetus, ensure that it is correctly 'positioned' and facilitate vaginal delivery. It has from anecdotal reports been known to result in premature rupture of membranes, abruptio placentae and uterine rupture. No statistically significant association was established between abdominal massage and preterm delivery in this study $(p<0.111$ ), however parturients who had abdominal massage in this study were twice as likely to have preterm delivery compared to those who did not.

Complications of preterm birth are the leading direct cause of neonatal mortality, accounting for an estimated $27 \%$ of the almost four million neonatal deaths annually, and act as a risk factor for many neonatal deaths due to other causes, particularly infections. ${ }^{4}$ This study was carried out in two centres, DELSUTH, Oghara and Central Hospital, Warri. There were statistically significant differences in foetal salvage rates between gestational age categories in DELSUTH $(p=0.009)$ and Central Hospital Warri $(p=0.001)$. Two deliveries were recorded below 28weeks in Central Hospital, Warri and one in DELSUTH, Oghara. These babies died before the $8^{\text {th }}$ day post-delivery, giving a $100 \%$ case fatality rate.

While the distribution of deliveries in the very preterm, moderate and late preterm categories in DELSUTH was skewed towards the early preterm category with a fetal salvage rate of $54.5 \%$, the same could not be said of Central Hospital, Warri where the bulk of preterm deliveries was in the late preterm category with a fetal salvage rate of $95.9 \%$. Kuti and colleagues ${ }^{28}$ from South - west Nigeria in their study on gestational age-specific neonatal mortality among preterm singleton births, recorded $100 \%$ case fatality rate in babies born before 28 weeks gestation. This was attributed mainly to respiratory distress syndrome. This was similar to the findings of Ugwu et al. ${ }^{5}$ and Ugwu et al. ${ }^{29}$, both from the South - south region of Nigeria. Trotman et al. ${ }^{30}$ working from the West Indies recorded a $97 \%$ case fatality rate for babies born before 27 weeks gestation. On a global scale, the World Health Organization has determined that half the babies born at 32 weeks gestation continue to die due to lack of feasible, cost effective care such as warmth, breast feeding support and basic care for infections as well as breathing difficulties. ${ }^{14}$

The results of the present case-control study could be faulted on the basis that significant information obtained was based on self-reporting of events rather on more robust outcome indicators except for the clinical assessment and laboratory investigations. However, selfreporting of perinatal adverse outcomes has proven useful within the context of developing countries as the cohort of cases would be well motivated to be forthright and recall as much as possible correctly in the bid of seeking solutions to the challenge of their reproductive career.

Additionally, we believe that a careful interviewing procedure and a detailed explanation of the study protocol limited recall bias. Furthermore, although women with preterm deliveries and adverse perinatal outcomes may be better motivated to report a history of past preterm deliveries and perinatal morbidities and mortality, this was nevertheless counterbalanced by the detailed and sensitive interviewing of both cases and controls. Thus, we believe that the results of the present study are valid and make an important contribution to understanding the problems of preterm deliveries and its associated clinical and socio-demographic variable in Nigeria.

\section{CONCLUSION}

In conclusion, this study showed that preterm births continue to be a major public health concern with a reported incidence rate of $16 \%$. Premature rupture of 
membrane was the strongest predictor of preterm birth. The study failed to show a strong independent association between sociodemographic variables and the risk of preterm birth, except for parity.

In terms of gestational age specific fetal salvage rates, this was zero for extremely preterm neonates with significant difference in fetal salvage rates across the categories of preterm neonates. Efforts to address the foregoing factors, which are predictors of preterm births and health-seeking behaviour with a view to achieving increased awareness and utilization of antenatal care among the female population will likely contribute to reducing the burden of preterm delivery in Nigeria and by extension other developing nations.

\section{ACKNOWLEDGEMENT}

We acknowledge the support of the doctors and nursing staff of the departments of Obstetrics and Gynecology, and the neonatal units of the Central Hospital Warri and DELSUTH Oghara for their kind support and cooperation during the period of the data collection. We are also grateful to Dr. Ayotunde Adeyinka for his editorial and proof-reading inputs into this manuscript.

\section{REFERENCES}

1. Ogilvie G, Vancouver BC, Mundle WR. Antibiotic Therapy in Preterm Premature Rupture of the Membranes. JOGC SOGC Clin Pract Guidel. 2009;(233):863-7.

2. National Population Commission (NPC) Nigeria IM. Nigeria Demographic and Health Survey 2008. 2009.

3. Anorlu RI, Igwilo CI, Iroha E, Odum CU. Maternal Risk Factors for preterm delivery in lagos. Nig Ot J Hosp Med. 2003;13(3-4):6-10.

4. Lawn JE, Gravett MG, Nunes TM, Rubens CE, Stanton C, Group R. Global report on preterm birth and stillbirth (1 of 7): definitions, description of the burden and opportunities to improve data. $B M C$ Pregnancy Childbirth. 2010;10(1):1-22.

5. Ugwu GIM. Factors associated with Prematurity in Warri Niger Delta; an eight year review. Cont J Trop Med. 2009;3:22-8.

6. World Health Organization. Preterm birth Fact sheet $\mathrm{N}^{\circ} 363.2012$.

7. Etuk SJ, Etuk JS, Oyo-Ita AE. Factors Influencing the Incidence of Pre-term Birth in Calabar, Nigeria. Niger J Physiol Sci. 2005;20(1-2):63-8.

8. Osaikhuwuomwan JA. Preterm rupture of membranes: The Vitamin C Factor. Rev Artic. 2010;12(1):60-8.

9. Boafor $\mathrm{T}$, Nkyekyer $\mathrm{K}$, Enweronu-Laryea C. Singleton Preterm Births in Korle Bu Teaching
Hospital, Accra, Ghana - Origins and Outcomes. Ghana Med J. 2006;40(3):93-8.

10. Mokuolu OA, Abdul IF, Adesiyun O. Maternal Factors Associated with Early Spontaneous Singleton Preterm Delivery in Nigeria. Trop J Obstet Gynaecol. 2002;19(1):32-5.

11. Mokuolu OA, Suleiman BM, Adesiyun OO, Adeniyi A. Prevalence and determinants of preterm deliveries in the University of Ilorin Teaching Hospital, Ilorin, Nigeria. Pediatr Rep. 2010;2(1):114.

12. Institute of Medicine of the National Academies. Preterm Birth: Causes, Consequences, and Prevention. Behrman RE, Butler AS, editor. 2007. 1$741 \mathrm{p}$.

13. Dolatian M, Mirabzadeh A, Forouzan AS, Sajjadi H, Alavi Majd H, Moafi F. Preterm Delivery and Psycho-Social Determinants of Health Based on World Health Organization Model in Iran: A Narrative Review. Glob J Health Sci. 2012 ;5(1):5264.

14. World Health Organization. Born too soon. The Global Action Report on Preterm Birth. 2012

15. Offiah I, O’Donoghue K, Kenny L. Clinical Risk Factors for Preterm Birth. In: Morrison J, editor. Preterm Birth - Mother and Child. 1st ed. InTech; 2012. p. 73-94.

16. Blencowe H, Cousens S, Oestergaard MZ, Chou D, Moller A-B, Narwal R, et al. National, regional, and worldwide estimates of preterm birth rates in the year 2010 with time trends since 1990 for selected countries: a systematic analysis and implications. Lancet. Elsevier Ltd; 2012;379(9832):2162-72.

17. Kunle-Olowu OE, Peterside O, Adeyemi OO. Prevalence and Outcome of Preterm Admissions at the Neonatal Unit of a Tertiary Health Centre in Southern Nigeria. Open J Pediatr. 2014;4:67-75.

18. Shubhada S, Kambale S, Phalke B. Determinants of Preterm Labour in a Rural Medical College Hospital in Western Maharashtra. Nepal J Obstet. 2013;8(1):31-3.

19. Oyedeji GA. Socio - economic and Cultural Background of Hospitalized Children in Ilesha. Niger J Paediatr. 1985;12(4):111-7.

20. http://www.openepi.com/SampleSize/SSCC.htm.

21. Ezechi OC, Makinde ON, Kalu BEK, Nnatu SNN. Risk factors for preterm delivery in south western Nigeria. $J$ Obstet Gynaecol (Lahore). 2003;23(4):387-91.

22. Bakhteyar K, Lorzadeh N, Pournia Y. Factors associated with preterm delivery in women admitted to hospitals in Khorramabad: A case control study. Int J Heal Allied Sci. 2012;1(3):147-52.

23. Umeora OUJ, Ande ABA, Onuh SO, Okubor PO, Mbazor JO. Incidence and risk factors for preterm 
delivery in a tertiary health institution in Nigeria. $J$ Obstet Gynaecol. 2004;24(8):895-6.

24. Omole-Ohonsi A, Attah R. Risk Factors of Preterm Deliveries at Aminu Kano Teaching Hospital, Kano, Nigeria. South Asian J Med Sci. 2012;1(1):3-10.

25. Hayat M, Kareem R, Hussain M, Ali N, Khan B. Risk Factors for Preterm Births in a Tertiary Care Hospital, Lady Reading Hospital, Peshawar. J Postgr Med Inst. 2012;26(2):158-64.

26. Hamad KA. Risk factors associated with preterm birth in the Gaza Strip: hospital-based case-control study. East Mediterr Heal J. 2007;13(5):1132-41.

28. Kuti O, Owa JA. Gestational age-specific neonatal mortality among preterm singleton births in a
Nigerian tertiary institution. Int J Gynecol Obstet. 2003;80(3):319-20.

29. Ugwu R, Eneh A. The Proportion Of Low Birth Weight Babies Due To Small For Gestational Age (SGA) And Prematurity In Port Harcourt, SouthSouth Nigeria-Changing Trends. Internet J Pediatr Neonatol. 2011;13(1).

30. Trotman H, Lord C. Outcome of Extremely Low Birthweight Infants at the University Hospital of the West Indies, Jamaica. West Indian Med J. 2007;56(5):409-13.

Copyright (C) The Author(s). This is an Open Access article under the CC BY license. 